\title{
A Multicenter Study Assessing Risk Factors and Aeroallergens Sensitization Characteristics in Children with Self-Reported Allergic Rhinitis in China
}

Liting Wu, ${ }^{1} *$ Wenting Luo, ${ }^{1}, *$ Haisheng Hu, 'Xianhui Zheng, Zhangkai J Cheng, (D)

Dongming Huang, ${ }^{2}$ Xiaowen Huang, ${ }^{2}$ Hong Zhang, ${ }^{3}$ Yang Liu, ${ }^{3}$ Rongfang Zhang, Hui Yang, ${ }^{4}$ Yun Sun, ${ }^{5}$ Yi Wang, JinHai Ma, ${ }^{6}$ Jing Liu, ${ }^{6}$ Xin Sun, Huajie Wu, ${ }^{7}$ Chunhua Wei, ${ }^{8}$ Shuping Zhang, ${ }^{8}$ Xiaoluan $\mathrm{Li}^{9}{ }^{9}$ Shuang Ren, ${ }^{9}$ Chuangli Hao, ${ }^{10}$ Baoqing Sun (ID)

'Department of Allergy and Clinical Immunology, State Key Laboratory of Respiratory Disease, National Clinical Research Center of Respiratory Disease, Guangzhou Institute of Respiratory Health, First Affiliated Hospital of Guangzhou Medical University, Guangzhou Medical University, Guangzhou, Guangdong, 510120, People's Republic of China; ${ }^{2}$ Department of Pediatrics, Boai Hospital of Zhongshan City, Zhongshan, 528400, People's Republic of China; ${ }^{3}$ Gansu Provincial Hospital, Lanzhou, 730000, People's Republic of China; ${ }^{4}$ Gansu Provincial Maternity and Child Care Hospital, Lanzhou, 730000, People's Republic of China; ${ }^{5}$ inchuan Maternal and Child Health Care Hospital, Yinchuan, 750000, People's Republic of China; ${ }^{6}$ Ningxia Medical University General Hospital, Yinchuan, 750000, People's Republic of China; ${ }^{7}$ Department of Pediatrics, Xijing Hospital, the Fourth Military Medical University, Xian, 7I0032, People's Republic of China; ' ${ }^{2}$ Weifang Weien Hospital, Weifang, 261000, People's Republic of China; ${ }^{9}$ The First Hospital of Hebei Medical University, Shijiazhuang, 050000, People's Republic of China; ${ }^{10}$ Department of Respirology, Children's Hospital, Soochow University, Suzhou, 215025, People's Republic of China

*These authors contributed equally to this work

Correspondence: Baoqing Su

First Affiliated Hospital of Guangzhou Medical University, 151 Yanjiangxi Road, Guangzhou,

510120 , Guangdong, People's Republic of China

Tel +862083062865

Fax +86208306 2729

Email sunbaoqing@vip.163.com

Chuangli Hao

Department of Respirology, Children's Hospital, Soochow University, Suzhou, 2I5025, Jiangsu,

People's Republic of China

Tel +86-5 I 280693588

Fax +86-5I 2-80696309

Email hcl_md@I63.com
Background: Up to now, epidemiological studies on allergy rhinitis (AR) have primarily focused on determining the risk of disease in Chinese adults, with the majority of them designed by single centers, while cross-sectional and epidemiological data describing allergic sensitization in children with self-reported AR are scarce.

Objective: This study was estimating of the latest information about the sensitization patterns and risk factors of clinical AR to develop effective strategies for the prevention and treatment of AR.

Methods: We conducted a cross-sectional survey between January 2020 and June 2021 involving children from seven cities in China who reported AR. A total of 762 children participated in this survey. To evaluate the risk factors and specific sensitization patterns of clinical AR through questionnaires and specific immunoglobulin E to 11 aeroallergens.

Results: Of the 762 patients, $593(77.8 \%)$ had at least one positive IgE level. Aged 7-14 years (OR 1.503, (95\% CI 1.058-2.136), $P=0.023)$; With allergic conjunctivitis (OR 1.843, (95\% CI 1.297-2.620), $P=0.001)$ and living in the Eastern (OR 1.802, (95\% CI 1.2632.573), $P=0.001$ ) all elevated the risk of clinical AR associated with aeroallergens. The sensitization rates of $D$. pteronyssinus and $D$. farinae were higher than those of other allergens in the $0-6$ and 7-14 years old age groups. The most common aeroallergens among self-reported children with $\mathrm{AR}$ in the eastern were D. farinae $(74.9 \%)$ and D. pteronyssinus $(74.3 \%)$, while in the western were mugwort $(60.0 \%)$ and marguerite $(56.6 \%)$. Majority of sIgE-positive subjects were sensitized to three or more of the tested pollen allergens in the Western (52.1\%), compared with 5.7\% in the Eastern.

Conclusion: There was an apparent geographic variation in childhood allergies in China. Age factors also had strong impacts on the allergen sensitization rate of children, but these impacts differed across regions.

Keywords: allergic rhinitis, specific immunoglobulin E, cross-sectional survey, aeroallergen, children

\section{Introduction}

Allergic rhinitis (AR) is caused by immunoglobulin E (IgE)-mediated reactions to allergens, ${ }^{1,2}$ affecting $10 \%$ to $40 \%$ of the population in the world. ${ }^{3}$ Allergen sensitization is an important risk factor for $\mathrm{AR},{ }^{4}$ which poses a substantial health risk to children and affects their quality of life. ${ }^{5,6}$ Allergen sensitization in preschool and school-age children is closely related to allergen. ${ }^{7}$ Exposures to aeroallergen may aggravate the symptoms of rhinitis ${ }^{8-10}$ and asthma by promoting airway inflammation and airway hyperresponsiveness and airflow restriction. ${ }^{11,12}$ The epidemiological investigation of 
allergic rhinitis is helpful to identify potential aeroallergen and assist clinicians in accurate diagnosis and treatment of the disease.

A series of studies have explored the prevalence of allergen sensitization in China, such as Li et al ${ }^{13}$ assessed the prevalence of sensitizations by Skin prick tests (SPT) in patients with asthma and/or rhinitis in China from 2006 to 2007 and demonstrated significant differences in patterns of sensitizations from different geographical areas. However, in the vast territory of China, few multicenter studies have focused on sensitization to aeroallergens in children with AR. In addition, China's modernization, growing urbanization, changing lifestyles and climatic factors have further complicated geographical variations in the distribution of allergens. Sensitive patterns of the population are also evolving and need to be assessed regularly. Therefore, there is a strong need for a study to estimate the latest information about the sensitization patterns and risk factors of clinical AR to develop effective strategies for the prevention and treatment of AR in China, not just in a specific geographic region of China.

In this cross-sectional survey, we measured specific IgE to 11 aeroallergens in children with self-reported AR within China, analyzed the statistical variables of the patient population, allergen exposure, and serum-specific IgE sensitization, and then assessed the risk factors and sensitization characteristics of allergic rhinitis associated with aeroallergens.

\section{Materials and Methods}

\section{Patients and Study Design}

Research population: This cross-sectional (retrospective analysis) study was conducted in seven cities and nine centers, respectively, in eastern and western China between January 2020 and June 2021. These cities are Weifang in Shandong, Zhongshan in Guangdong, Suzhou in Jiangsu, Shijiazhuang in Hebei, Lanzhou in Gansu, Xijing in Shaanxi and Yinchuan in Ningxia in western China. Clinicians in nine centers collected medical history, questionnaires and serum examinations from children aged 0 to 14 who self-reported allergic rhinitis. There were 527 males and 235 females, with a median age (interquartile interval) of $7.00(5.00,10.0)$ years. According to their age, they were divided into two groups: $0-6$ yr age group $(n=333)$ and $7-14$ yr age group $(n=429)$. Classic symptoms of AR include sneezing, nasal congestion, rhinorrhea, and nasal pruritus, alongside ocular symptoms, such as redness and itching of eyes and lachrymation. NAR is a group of heterogeneous diseases, characterized by clinical nasal symptoms with negative specific allergen tests, ${ }^{14}$ while Clinical AR with typical symptoms of AR and can be detected with IgE against relevant aeroallergens. The self-reported AR subjects were further divided into two groups: $\operatorname{sIgE}$ positive subjects were defined as clinical AR patients and SIgE negative subjects were defined as clinical NAR patients.

\section{Questionnaire}

The questionnaire used in the survey was adopted from the Chinese-translated version ${ }^{15}$ of the questionnaire from International Study of Asthma and Allergies in Childhood Phase II, $^{16}$ and modifications were made according to the real situation of China. Questions about demographic characteristics; family history of allergic diseases; symptoms of rhinitis, wheezing, or coughing; burning or itchy eyes; and environmental exposure factors were asked. AR was diagnosed according to the criteria of 2010 aria guidelines, ${ }^{17}$ if the subject had more than two of the following four typical rhinitis symptoms, he/she was defined as a self-reported AR patient. Such symptoms included sneezing, runny nose, nasal congestion and itching over the past 12 months, and excluded the effects of upper respiratory tract infection. All the selected patients signed a written informed consent in duplicate by themselves or their legal guardian before the study.

\section{Blood Collection, Serum Processing and Storage}

Serum samples from patients were obtained by 10 -minute centrifugation at $3000 \mathrm{~g}$ of venous blood collected with a separation gel containing vacutainer tubes. Aliquots of serum were stored at $-80^{\circ} \mathrm{C}$ in AIR-SKLRD. The serum samples were analysed with the ALLEOS $2000^{\mathrm{TM}}$ allergen detection system (Hycor Biomedical, USA). Allergic sensitization was defined as at least one positive sIgE. A positive result was defined as an IgE level of $0.35 \mathrm{kU} /$ $\mathrm{L}$ or more for the specific allergen. The allergens tested were those known to be present in China. We grouped these allergens according to shared characteristics: pollens (birch, timothy, mugwort, marguerite, dandelion, plantain), animals (cat, dog, horse), mites (D. pteronyssinus and D. farina). 


\section{Statistical Analysis}

Data were analyzed using SPSS V.22 software package (IBM Corp., Armonk, NY, USA). Descriptive statistics were used to study the demographic and general information of the study population. Geographical areas and age groups were treated as categorical variables. Chisquare analysis was performed to analyze the clinical evaluation and the sensitised allergens evidenced by sIgE. Univariate analysis was used, followed by multivariate logistic regression, to evaluate the associated factors of clinical AR and NAR. Both the OR and the 95\% CI were measured. A value of $P<0.05$ was considered to be significant. The differential variables with $P<0.05$ were included in the model together with gender and disease. The correlation of different allergens was analyzed by Spearman's test.

\section{Results}

\section{Characteristics Between Clinical NAR and Clinical AR}

A total of 762 children were recruited for this study, including 527 males and 235 females. The mean age of the sample was 7.59 years (SD, 3.15); Table 1 shows the demographic characteristics of the study population, $593(77.8 \%)$ sensitised to at least one aeroallergen. By univariate analysis, clinical AR in the 7-14 yr age group was higher than that in the $0-6 \mathrm{yr}$ age group $(41.1 \%$ vs $58.9 \%, P=0.008)$; in the East was higher than that in the West $(53.0 \%$ vs $47.0 \%, P=0.004)$; Conjunctivitis was higher than that without conjunctivitis $(57.3 \%$ vs $42.7 \%, P=0.001)$. The above differential variables and the two confounding factors of gender and self-reported asthma were included in the logistic regression equation. The children aged 7 to 14 years (OR 1.503, (95\% CI 1.058-2.136), $P=0.023$ ); Children with conjunctivitis (OR 1.843, (95\% CI 1.297-2.620), $P=0.001$ ) and living in the eastern region (OR 1.802, (95\% CI 1.263-2.573), $P=0.001$ ) increased the risk of AR associated with inhaled allergens. As shown in Table 2, living in the eastern region, 7-14 years old and allergic conjunctivitis (AC) are independent risk factors for children with AR related to inhaled allergens.

\section{The Patterns of Sensitization to Allergens in the Environment Differ Widely in Different Regions}

As shown in Figure 1, the most common sensitising allergens were $D$. farinae $(74.9 \%)$ and $D$. pteronyssinus $(74.3 \%)$ in the Eastern, while in the Western were mugwort (60.0\%) and marguerite (56.6\%). There was a similar trend in the eastern sub-analysis of 0-6 years old, pollen sensitization was more common in the Western than in the Eastern $(P<0.05)$ (see Appendix 1). We also compared allergen exposure to plants and hairy animals in different regions, and found that people in the Western had more contact with plants than people in the Eastern $(52.3 \%$ vs $47.7 \%, P<0.001)$. After exposure to plants, people are more likely to develop nasal symptoms such as nasal itching, nasal congestion or sneezing $(22.2 \%$ vs $42.5 \%$, $P<0.001)$ and lung symptoms $(10.10 \%$ vs $26.60 \% P<$ $0.001)$. There was no significant difference between eastern and western populations in contact with cat or dog, but people in the Western were more likely to develop nasal symptoms $(29.4 \%$ vs $13.4 \%, P<0.001)$ and pulmonary symptoms $(23.5 \%$ vs $6.7 \%, P<0.001)$. We also found that the use of air conditioners in the Eastern reached almost $99 \%$, which was much higher than that in the Western (98.2\% vs $38.9 \%, P<0.001)$.

\section{The Patterns of Sensitization to Allergens in Different Age Groups}

Figure 2 shows the sensitization rate of mite was most common in both age groups. Prevalence rates for cat and dog, the 7-14 yr age group, were significantly higher than the $0-6$ yr age group $(P<0.05$ for each). A sub-analysis of tested patients residing in eastern indicated that those aged 0-6 years were less commonly sensitised to cat, horse or dog aeroallergens than patients aged $7-14$ yr $(P<0.05$ for each), however only cat sensitization in the $7-14 \mathrm{yr}$ age group was higher than that in the $0-6 \mathrm{yr}$ age group in the Western $(P=0.001)$ (Appendix 2).

\section{Eastern and Western with Multi-Sensitization}

Of the 762 patients who had undergone testing for all 11 allergen groups, $350(13.8 \%)$ were only sensitised to the pollen allergen group, with Eastern and Western 
Table I Demographic and Clinical Characteristics of the Clinical NAR $(N=169)$ and Clinical AR $(N=593)$

\begin{tabular}{|c|c|c|c|c|c|}
\hline \multirow[t]{3}{*}{ Characteristic } & & \multicolumn{2}{|c|}{ Self-Reported Allergic Rhinitis } & \multirow{3}{*}{ Total $(\mathbf{N}=762)$} & \multirow[t]{3}{*}{$P$} \\
\hline & & Clinical NAR & Clinical AR & & \\
\hline & & n (\%) ${ }^{a}$ & n (\%) ${ }^{b}$ & & \\
\hline \multirow[t]{2}{*}{ Region } & Eastern & $68(40.2)$ & $314(53.0)$ & $382(50.13)$ & 0.004 \\
\hline & Western & 101 (59.8) & $279(47.0)$ & $380(49.87)$ & \\
\hline \multirow[t]{2}{*}{ Age (years) } & $0-6$ & 89 (52.7) & $244(4 I .1)$ & $333(43.70)$ & 0.008 \\
\hline & $7-14$ & $80(47.3)$ & 349 (58.9) & $429(56.30)$ & \\
\hline \multirow[t]{2}{*}{ Gender } & Female & $58(34.3)$ & 177 (29.8) & $235(30.84)$ & 0.267 \\
\hline & Male & III (65.7) & $416(70.2)$ & $527(69.16)$ & \\
\hline \multirow[t]{2}{*}{ Ethnic } & Other & $10(5.9)$ & $37(6.2)$ & $47(6.17)$ & 0.878 \\
\hline & Han & $159(94.1)$ & $556(93.8)$ & 715 (65.88) & \\
\hline \multirow[t]{2}{*}{ Self-reported asthma } & No & $88(52.1)$ & $279(47.0)$ & $367(48.16)$ & 0.249 \\
\hline & Yes & 81 (47.9) & $314(53.0)$ & $395(51.84)$ & \\
\hline \multirow[t]{2}{*}{ Allergic conjunctivitis } & No & $97(57.4)$ & $253(42.7)$ & $260(34.12)$ & 0.001 \\
\hline & Yes & $72(42.6)$ & $340(57.3)$ & $502(65.88)$ & \\
\hline \multirow[t]{2}{*}{ Skin allergy } & No & $90(53.3)$ & 291 (49.1) & $381(50.00)$ & 0.337 \\
\hline & Yes & 79 (46.7) & $302(50.9)$ & $38 I(50.00)$ & \\
\hline \multirow[t]{2}{*}{ Birth mode } & Eutocia & $93(55.0)$ & $35 I(59.2)$ & 444 (58.27) & 0.333 \\
\hline & Cesarean & $76(45.0)$ & $242(40.8)$ & $318(41.73)$ & \\
\hline \multirow[t]{2}{*}{ Passive smoking } & No & $79(46.7)$ & $293(49.4)$ & $372(48.82)$ & 0.541 \\
\hline & Yes & $90(53.3)$ & $300(50.6)$ & $390(51.18)$ & \\
\hline \multirow[t]{2}{*}{ Family history } & No & $56(33.1)$ & $204(34.4)$ & $260(34.12)$ & 0.760 \\
\hline & Yes & $113(66.9)$ & $389(65.6)$ & $502(65.88)$ & \\
\hline \multirow[t]{2}{*}{ Location of the building } & Urban & $128(68.1 \%)$ & 404 (70.4\%) & $490(69.82)$ & 0.551 \\
\hline & Rural & $60(31.9 \%)$ & $170(29.6 \%)$ & $272(30.18)$ & \\
\hline \multirow[t]{2}{*}{ Residential floor } & $\leq 9$ floors & 118 (69.8) & $372(62.7)$ & $490(64.30)$ & 0.090 \\
\hline & $>9$ floors & $51(30.2)$ & $221(37.3)$ & $272(35.70)$ & \\
\hline \multirow[t]{2}{*}{ Air conditioner } & No & $63(37.3)$ & $176(29.7)$ & $239(31.36)$ & 0.060 \\
\hline & Yes & $106(62.7)$ & $4 I 7(70.3)$ & $523(68.64)$ & \\
\hline \multirow[t]{2}{*}{ Using mattress } & No & $17(10.1)$ & $46(7.8)$ & $63(8.27)$ & 0.338 \\
\hline & Yes & $152(89.9)$ & $547(92.2)$ & $699(91.73)$ & \\
\hline \multirow[t]{3}{*}{ QI } & No & $105(62.1)$ & $340(57.3)$ & $445(58.40)$ & 0.536 \\
\hline & Yes & $44(26.0)$ & $173(29.2)$ & $217(28.48)$ & \\
\hline & Never contact & $20(11.8)$ & $80(13.5)$ & $100(13.12)$ & \\
\hline \multirow[t]{3}{*}{ Q2 } & No & $129(76.3)$ & $409(69.0)$ & $538(70.60)$ & 0.141 \\
\hline & Yes & $20(11.8)$ & $104(17.5)$ & $124(16.27)$ & \\
\hline & Never contact & $20(11.8)$ & $80(13.5)$ & $100(13.12)$ & \\
\hline \multirow[t]{3}{*}{ Q3 } & No & $46(27.2)$ & $179(30.2)$ & $225(29.53)$ & 0.126 \\
\hline & Yes & $8(4.7)$ & $52(8.8)$ & $60(7.87)$ & \\
\hline & Never contact & $115(68.0)$ & $362(61.0)$ & $477(62.60)$ & \\
\hline
\end{tabular}

(Continued) 
Table I (Continued).

\begin{tabular}{|l|c|c|c|c|c|}
\hline \multirow{2}{*}{ Characteristic } & \multirow{2}{*}{} & \multicolumn{2}{|c|}{ Self-Reported Allergic Rhinitis } & \multirow{2}{*}{ Total (N=762) } & \multirow{2}{*}{$\boldsymbol{P}$} \\
\cline { 3 - 5 } & & Clinical NAR & Clinical AR & \multirow{2}{*}{} \\
\cline { 3 - 5 } & & $\mathbf{n}(\%)^{\mathbf{a}}$ & $\mathbf{n}(\%)^{\mathbf{b}}$ & & \\
\hline \multirow{2}{*}{ Q4 } & No & $48(28.4)$ & $195(32.9)$ & $243(31.89)$ & 0.185 \\
& Yes & $6(3.6)$ & $36(6.1)$ & $42(5.51)$ & \\
& Never contact & $115(68.0)$ & $362(61.0)$ & $477(62.60)$ & \\
\hline
\end{tabular}

Notes: a'Self-reported AR subjects showing negative IgE. belf-reported AR subjects with positive lgE. QI: Symptoms of itching, stuffy nose or snorting after contact with grass, trees or flowers. Q2: Symptoms of dyspnea, wheezing, chest tightness, shortness of breath or cough after contact with grass, trees or flowers. Q3: Symptoms of itching, stuffy nose or snorting after contact with dogs or cats. Q4: Symptoms of dyspnea, wheezing, chest tightness, shortness of breath or cough after contact with dogs or cats. $P$ value significant at $<0.05$.

accounting for $100(26.2 \%)$ and $250(65.8 \%)$, respectively. There was a significant correlation between tree, grass and weeds. Among them, the correlation between mugwort and marguerite was the strongest $(\mathrm{r}=0.893, P<0.05)$, while timothy and mugwort was the weakest $(\mathrm{r}=0.651$, $P<0.05$ ) (Table 3). Most of the patients in the Western showed sensitization to weeds (mugwort, marguerite, dandelion, plantain), birch and timothy. The majority of sIgEpositive subjects were sensitized to three or more of the tested pollen allergens in the Western (52.1\%), compared with $5.7 \%$ in the eastern only. $95.4 \%(122 / 128)$ of patients with sensitization to timothy also had sensitization to weeds, and only $4.6 \%(6 / 128)$ were mono-sensitive to timothy in the Western (Figure 3A), while 17.6\% (3/17) in the Eastern (Figure 3B). Of the 94 (24.7\%) sensitised to birch in the Western, $94(100 \%)$ were sensitised to both birch and weeds (Figure 3C); even a small number of birch sensitized patients in the Eastern, but 22.2\% (4/18) patients were sensitised to birch only (Figure 3D). Of the 285 sensitised to marguerite, 2 (1.3\%) was monosensitised to marguerite in the Western, while $21(30 \%)$

Table 2 Risk Factors (Odds Ratio (OR)) for Clinical AR

\begin{tabular}{|l|c|c|c|c|}
\hline \multirow{2}{*}{ Factors } & \multicolumn{4}{|c|}{ Clinical AR } \\
\cline { 2 - 5 } & $\boldsymbol{\beta}$ & $\boldsymbol{P}$ & OR & OR 95\% CI \\
\hline Male & 0.184 & 0.332 & 1.202 & $0.829-1.743$ \\
Eastern & 0.589 & 0.001 & 1.802 & $1.263-2.573$ \\
Age (7-14 years) & 0.408 & 0.023 & 1.503 & $1.058-2.136$ \\
Self-reported asthma & 0.216 & 0.230 & 1.241 & $0.872-1.766$ \\
Self-reported conjunctivitis & 0.611 & 0.001 & 1.843 & $1.297-2.620$ \\
\hline
\end{tabular}

Notes: Two confounding factors of gender (female or male) and self-reported asthma (yes or no) were included in the logistic regression analysis.

Abbreviations: Clinical AR, Self-reported AR subjects with positive $\operatorname{lgE} ; 95 \% \mathrm{Cl}$, $95 \%$ confidence intervals; $\beta$, regression coefficient. in the Eastern; Among 60\% (228/380) sensitised to mugwort in the Western, only $6.5 \%(15 / 228)$ were monosensitive to mugwort, $90.3 \%$ (206/228) also had sensitization to marguerite.

\section{Discussion}

We conducted an epidemiologic survey of self-reported AR and examined the sensitization rates against 11 aeroallergens by measuring the serum-specific IgE of 762 children in China.

Our results confirmed that the prevalence of clinical AR varied markedly between various regions and that this variation was more marked in the 7-14 age group. Interand intra-regional differences in climate, vegetation, air pollution levels, differences in lifestyle, pollen exposure, and genetic variability could be responsible for the variability. The current study showed that children with AC were 1.843 times more likely to develop clinical AR than those without AC (95\% CI:1.297-2.620). Indeed, it has been found that $\mathrm{AC}$ occurs concomitantly with $\mathrm{AR}$, which is consistent with current understanding. ${ }^{18,19}$

The study showed that the prevalence rates of sensitization to common inhaled allergens varied widely between regions. House dust mite (HDM) is the most important inhalant allergens in patients with self-reported AR in the Eastern, which is consistent with $\mathrm{Li}$ et al ${ }^{13}$ or Zhang et $\mathrm{al}^{20}$ previous studies in China. ${ }^{21}$ Zhongshan and Suzhou were located in subtropical areas with high temperatures and humidity throughout the year, with suitable temperature and humidity for dust mites to live. Li et $\mathrm{al}^{22}$ have reported that when the air conditioner is running, the mite allergens accumulate in the filter dust, increasing the allergic risk of rhinitis patients living in the room. Our data show that in the economically developed east, the air conditioning coverage rate reaches $99 \%$, so insufficient ventilation for indoor activities may increase the sensitization 


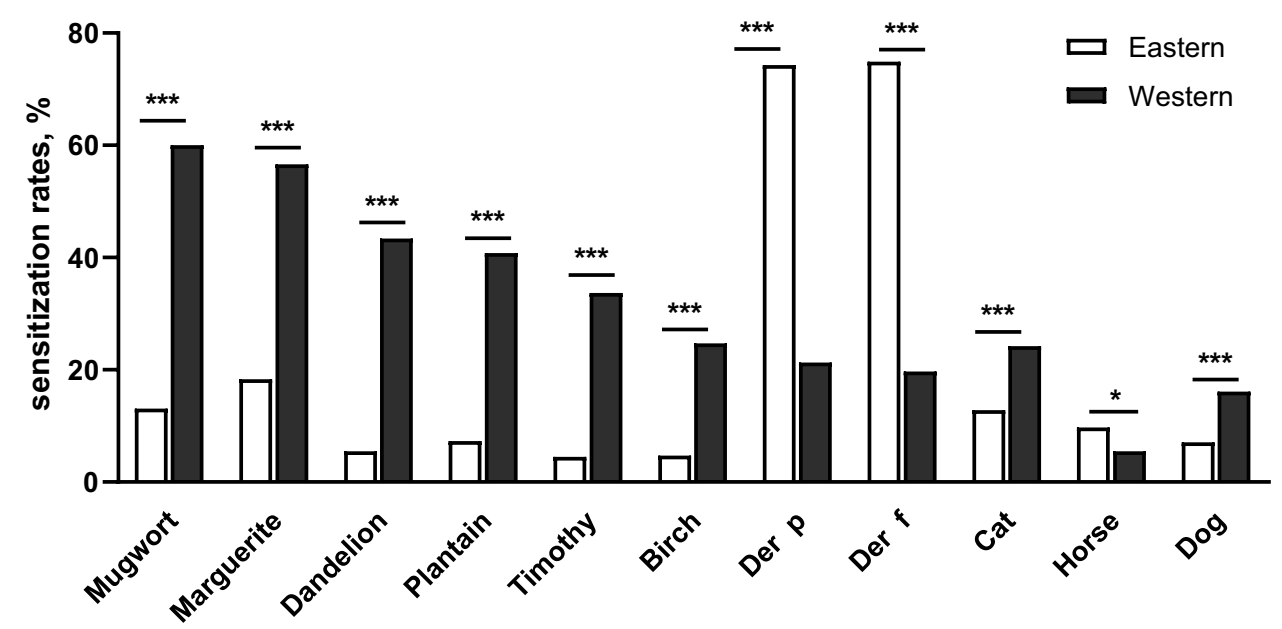

Figure I Prevalence (\%) of allergic sensitization defined by specific lgE level of $0.35 \mathrm{kU} / \mathrm{L}$ or more by geographic areas $(* \mathrm{P}<0.05, * * * \mathrm{P}<0.0 \mathrm{I})$.

rate of HDM. Patients living in the arid western region were more sensitive to pollen, which is similar to the result of the increased susceptibility of plants in Sydney's inland areas far from the coast. ${ }^{23}$

There are also geographical factors affecting animal sensitization. For cats and dogs, the sensitization rate in the Western is higher than that in the Eastern. In agreement with a previous multicenter cross-sectional study in Europe, there are significant differences in Fel d 1 levels in mattress dust of 2800 families in 22 urban areas in Europe. $^{24}$ Also, children in the Western region were more likely to have nasal symptoms $(29.4 \%$ vs $13.4 \%$, $P<0.001)$ and pulmonary symptoms $(23.5 \%$ vs $6.7 \%$, $P<0.001)$ than in the Eastern. This may be related to the fact that most people in the Western are more sensitized after exposure to cats and dogs. It is obvious that the prevalence of sensitisation to dogs and cats varies by region and predisposition to atopy.

The Western pastoral area is dominated by plateaus and mountains, and the natural vegetation is dominated by grasslands and deserts. Affected by those natural conditions, the rate of horse ownership is high, and horse riding is more popular in the Western than in the Eastern. However, our data show that horse sensitization is surprisingly higher in the Eastern. Of 113 atopic people in Italian cities, 60 horse sensitised patients complained that they had no contact with horses. ${ }^{25}$ This indicates that horse sensitization may also occur without significant direct or indirect contact with horses. We suspect that due to longterm contact with horses, immune tolerance is gradually established; thus, susceptible individual to horse is less common in the Western. What's more, people in the

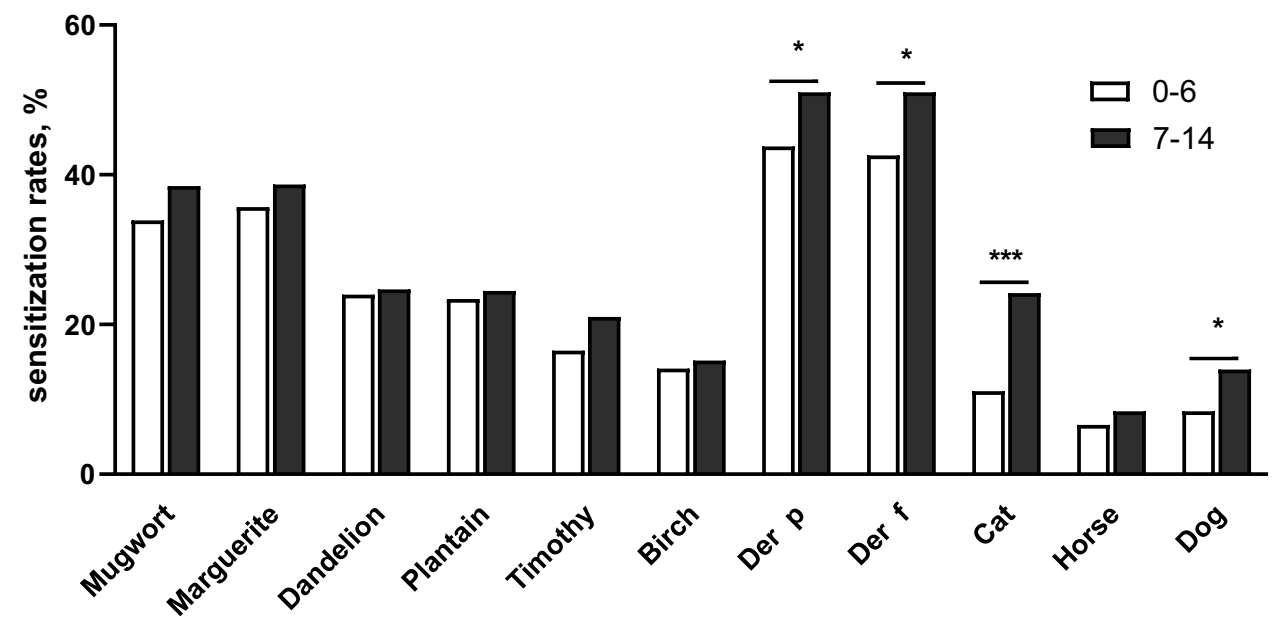

Figure 2 Prevalence (\%) of allergic sensitization defined by specific lgE level of $0.35 \mathrm{kU} / \mathrm{L}$ or more by age $(* \mathrm{P}<0.05, * * * \mathrm{P}<0.0 \mathrm{I})$. 
Table 3 Spearman Correlation Analysis of 6 Pollen Allergens IgE Concentrations

\begin{tabular}{|c|c|c|c|c|c|c|}
\hline Allergen & Mugwort & Marguerite & Dandelion & Plantain & Timothy & Birch \\
\hline Mugwort & I & & & & & \\
\hline Marguerite & $0.893 *$ & 1 & & & & \\
\hline Dandelion & $0.794 *$ & $0.863^{*}$ & 1 & & & \\
\hline Plantain & $0.753 *$ & $0.783 *$ & $0.811 *$ & 1 & & \\
\hline Timothy & $0.65 I^{*}$ & $0.689 *$ & $0.702^{*}$ & $0.778^{*}$ & I & \\
\hline Birch & $0.663 *$ & $0.695 *$ & $0.729 *$ & $0.808^{*}$ & $0.819 *$ & I \\
\hline
\end{tabular}

Notes: ${ }^{*} p<0.05$. Spearman Correlation analysis showed that there was a significant correlation between birch, timothy grass and weeds. The depth of the color between two allergens represented the degree of relationship between them.

eastern region may be indirectly exposed to serum albumin, an important panallergen involved in milk, meat and epithelia allergy, resulting in cross-reactivity. About half of the patients $(45.1 \%)$ reacted with two or all three animals as specified, the result is similar to study in Austria. ${ }^{26}$ To further verify cross-reaction and actual sensitization, it is necessary to develop allergen component detection in the future.

We also examined the role of age effects on the prevalence of aeroallergens. Subjects with self-reported aged 7 to 14 years were more sensitive to tested aeroallergens than aged $0-6$ years. In a cohort of an urban population of the center of Italy, the positive rate of prick test increased by $11.6 \%$ after about $6-10$ years of observation. ${ }^{27}$ The sensitization to common aeroallergens increased over time, which could be related to children's increasing outdoor activities as they become older, increasing their chances of being exposed to inhaled allergens. On the one hand, our findings showed that the sensitization rate of preschool and school-age children to HDM was high, and paediatricians should give children effective dust mite intervention measures to reduce indoor dust mite allergen exposure. On the other hand, children with respiratory allergic diseases were more sensitive to pollen in the Western, especially those over 6 years old, corresponding preventive measures should be taken. To our knowledge, trends in peak pollen times are measured during the spring, summer and autumn, which depends on the allergen source (trees, grass, and weeds). ${ }^{28}$ In China, birch tree pollen is one of the major portions in spring, while weed and grass pollen are the major portion in summer and autumn. ${ }^{29}$ It is necessary to wear masks or reduce outdoor exposure time during pollen seasons as well as weed pollen season.
A new finding of this study is that the co-sensitization rate of patients sensitized to pollen varied widely between the geographic areas. The majority of sIgE-positive subjects were sensitized to three or more of the tested pollen allergens in the Western (52.1\%), compared with $5.7 \%$ in the eastern only. This may be related to copious resources of vegetation in the western and arid, desert/steppe, cold arid climate, where pollens scattered with the wind and spread widely. In contrast, the eastern region is not conducive to the reproduction and spread of pollen, which is characterized by a single type of vegetation and high humidity. What's more, the high correlation and cosensitization of pollens suggested another reasonable explanation, that is parallel sensitization or crossreactivity between closely related allergens. Allergen components from different species may have the same functions. ${ }^{30}$ The sensitization of highly cross-reactive allergens (such as profilin, calcium-binding protein or cross-reactive carbohydrate determinants) in distant relatives may be the reason for the common sensitization of different allergens. Martin Canis pointed out that trees and grasses are structurally similar allergens that can be classified as taxonomic allergens, and patients with a representative allergy (such as birch and timothy) may also respond to other sources of this class (such as hazelnut and rye). ${ }^{31}$ Our data on $100 \%$ co-sensitization of birch sensitized patients with other pollen in the western region are consistent with this view. Thus, component-resolved diagnosis or molecular diagnosis is crucial to distinguish between cross-reaction and co-sensitization versus allergen immunotherapy decisions.

However, a major limitation of this study is the insufficient sample size. Affected by the epidemic of coronavirus disease 2019, number of outpatients has been greatly 


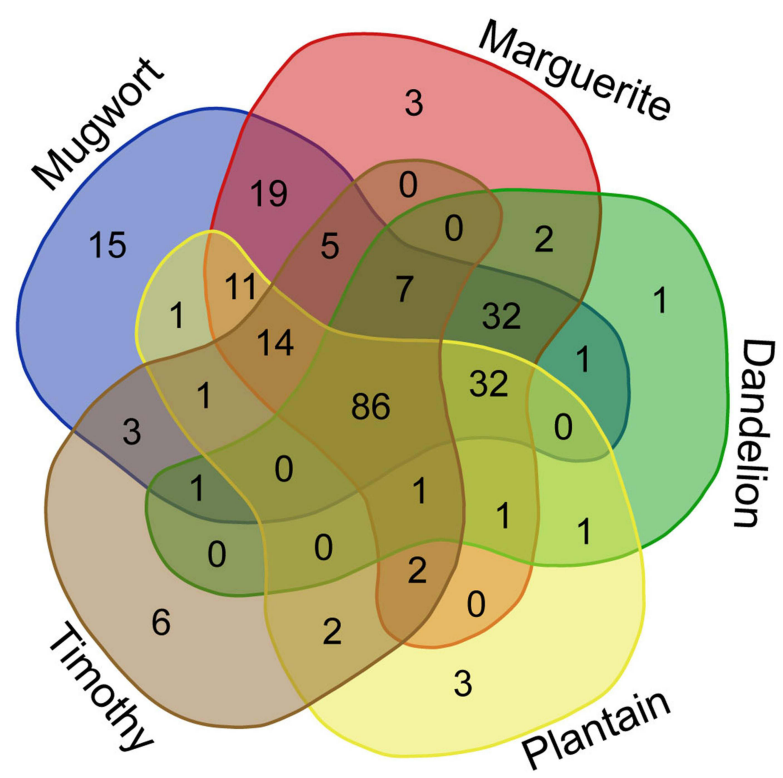

A

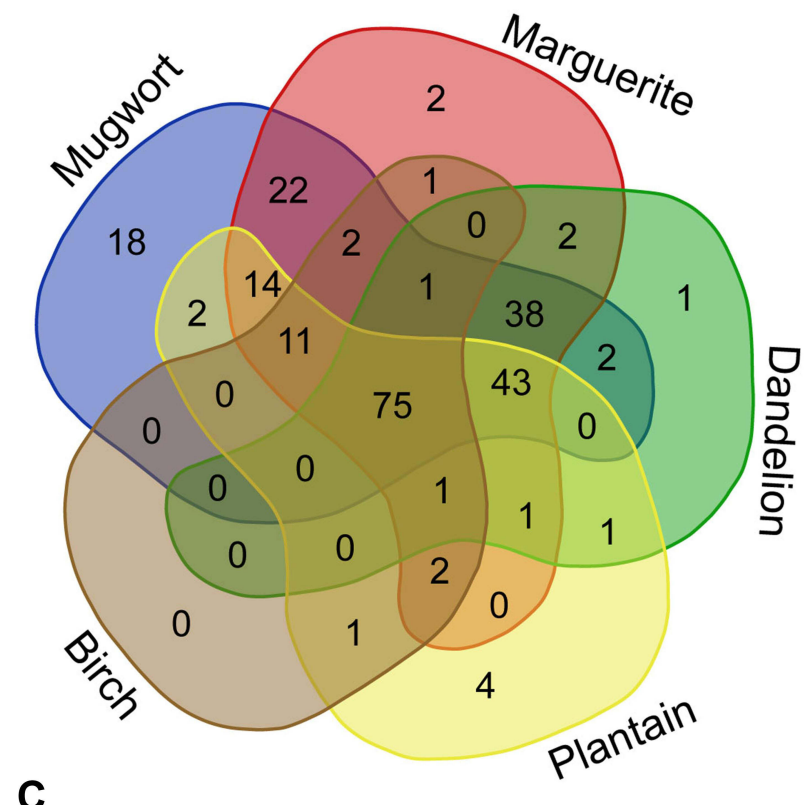

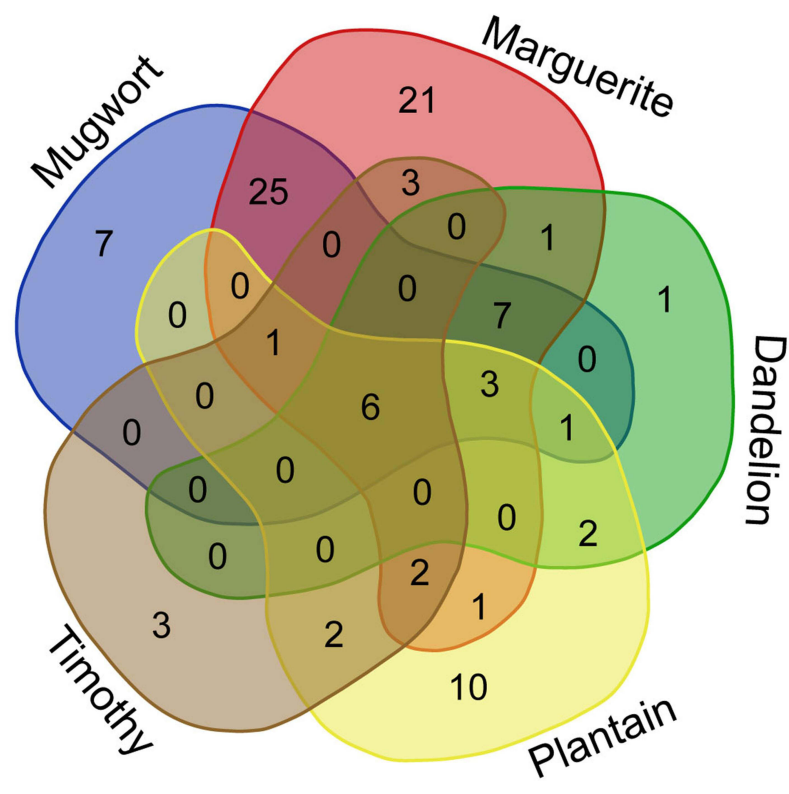

B

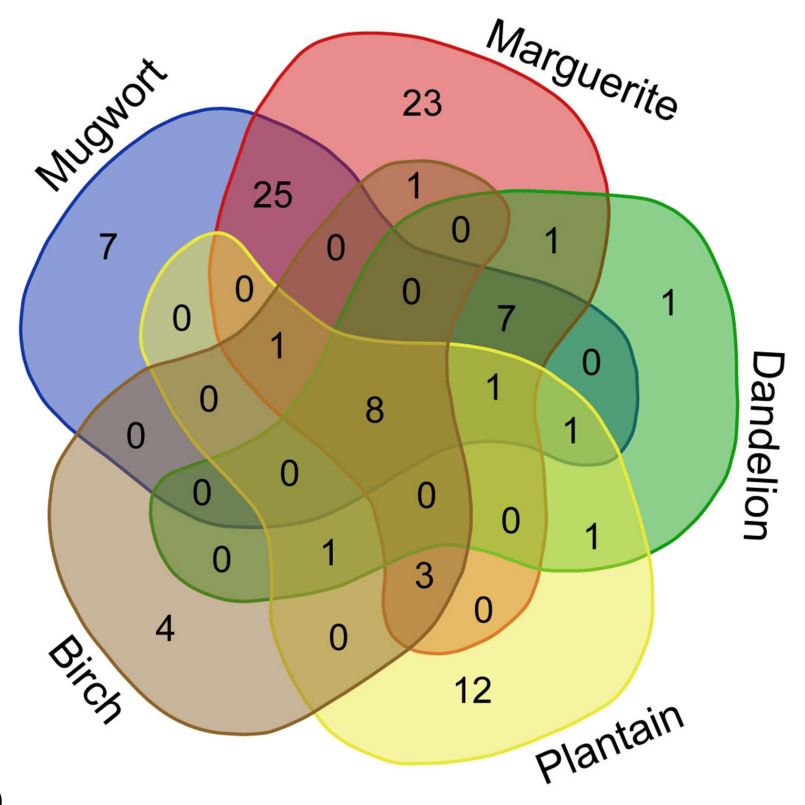

Figure 3 The co-sensitization between weeds pollen, timothy grass and birch. The Venn Diagram shows the number of patients what were co-sensitized. (A) The cosensitization between timothy grass and weeds pollen in the Western. (B) The co-sensitization between timothy grass and weeds pollen in the Eastern. (C) The cosensitization between birch and weeds pollen in the Western. (D) The co-sensitization between birch and weeds pollen in the Eastern.

reduced. ${ }^{32}$ The other reason is that only the centers with developed economies were included in the survey, and there are no clinical data about primary hospitals. Therefore, further studies including more individuals or the inclusion of economically backward areas in the future can better guide local allergen detection. In particular, the difference between NAR and AR was based only on typical rhinitis symptoms and the presence of $\operatorname{IgE}$, without data from SPT. In this respect, it is likely that the observed prevalence of NAR was higher than the actual prevalence. Self-described allergic rhinitis patients may not be $\operatorname{sgE}$ positive caused by allergens, but we do not rule out nonsIgE-mediated allergic rhinitis. However, because allergic and non-allergic rhinitis have different origins and treatments, using SIgE to divide people into allergic and nonallergic rhinitis could yield interesting results. ${ }^{33}$ 


\section{Conclusions}

In conclusion, the factors including age, geographical location and conjunctivitis were associated with $\mathrm{AR}$ related to inhaled allergens. Moreover, these risk factors interact with inhaled allergen sensitization rates. It provides an effective guiding basis for clinicians in the diagnosis and treatment of allergic diseases, and also provides reasonable health education materials for the prevention and treatment of allergic diseases in China.

\section{Ethics Approval and Consent to Participate}

This study was conducted in accordance with the declaration of Helsinki and approved by the ethics committee of the First Affiliated Hospital of Guangzhou Medical University (approval number: GYFYY-2017-18).

\section{Acknowledgments}

We thank everyone involved in the collection, detection, and date management of the serum samples.

\section{Funding}

This study was supported by the National Natural Science Foundation of China (81802076 and 81871736), SKLRD (MS-201906, Z-202209), Guangzhou Science and Technology Project of traditional Chinese Medicine and Integrated traditional Chinese and Western Medicine (20202A011017), and the Guangzhou Science and Technology Foundation (202102010327). Thanks to the Biobank for Respiratory Diseases at the National Clinical Research Center for Respiratory Disease (BRD-NCRCRD, Guangzhou, Southern China).

\section{Disclosure}

The authors declare that they have no competing interests in this work.

\section{References}

1. Bousquet J, Anto JM, Bachert C, et al. Allergic rhinitis. Nat Rev Dis Primers. 2020;6(1):95. doi:10.1038/s41572-020-00227-0

2. Meng Y, Wang C, Zhang L. Recent developments and highlights in allergic rhinitis. Allergy. 2019;74(12):2320-2328. doi:10.1111/ all.14067

3. Brozek JL, Bousquet J, Agache I, et al. Allergic rhinitis and its impact on asthma (ARIA) guidelines-2016 revision. J Allergy Clin Immunol. 2017;140(4):950-958. doi:10.1016/j.jaci.2017.03.050

4. Kurukulaaratchy RJ, Karmaus W, Arshad SH. Sex and atopy influences on the natural history of rhinitis. Curr Opin Allergy Clin Immunol. 2012;12(1):7-12. doi:10.1097/ACI.0b013e32834ecc4e
5. Larenas-Linnemann D, Pfaar O. Patient-reported outcomes and quality-of-life questionnaires in the assessment of rhinoconjunctivitis in childhood. Curr Opin Allergy Clin Immunol. 2014;14(3):192-199. doi:10.1097/ACI.0000000000000062

6. Campo P, Eguiluz-Gracia I, Bogas G, et al. Local allergic rhinitis: implications for management. Clin Exp Allergy. 2019;49(1):6-16. doi:10.1111/cea.13192

7. Brand PL, Baraldi E, Bisgaard H, et al. Definition, assessment and treatment of wheezing disorders in preschool children: an evidence-based approach. Eur Respir J. 2008;32(4):1096-1110. doi:10.1183/09031936.00002108

8. Jarvis D, Newson R, Lotvall $\mathrm{J}$, et al. Asthma in adults and its association with chronic rhinosinusitis: the GA2LEN survey in Europe. Allergy. 2012;67(1):91-98. doi:10.1111/j.13989995.2011.02709.x

9. Warm K, Hedman L, Lindberg A, Lotvall J, Lundback B, Ronmark E. Allergic sensitization is age-dependently associated with rhinitis, but less so with asthma. J Allergy Clin Immunol. 2015;136(6):1559-1565 e1552. doi:10.1016/j.jaci.2015.06.015

10. Wu TJ, Chen BY, Lee YL, Hsiue TR, Wu CF, Guo YL. Different severity and severity predictors in early-onset and late-onset asthma: a Taiwanese population-based study. Respiration. 2015;90 (5):384-392. doi:10.1159/000439310

11. Gruchalla RS, Pongracic J, Plaut M, et al. Inner City Asthma Study: relationships among sensitivity, allergen exposure, and asthma morbidity. $J$ Allergy Clin Immunol. 2005;115(3):478-485. doi:10.1016/j.jaci.2004.12.006

12. Godeau D, Petit A, Richard I, Roquelaure Y, Descatha A. Return-to-work, disabilities and occupational health in the age of COVID-19. Scand $J$ Work Environ Health. 2021;47(5):408-409. doi:10.5271/sjweh.3960

13. Li J, Sun B, Huang Y, et al. A multicentre study assessing the prevalence of sensitizations in patients with asthma and/or rhinitis in China. Allergy. 2009;64(7):1083-1092. doi:10.1111/j.13989995.2009.01967.x

14. Greiwe J, Bernstein JA. Nonallergic rhinitis: diagnosis. Immunol Allergy Clin North Am. 2016;36(2):289-303. doi:10.1016/j.iac.2015.12.006

15. Wong GW, Ko FW, Hui DS, et al. Factors associated with difference in prevalence of asthma in children from three cities in China: multicentre epidemiological survey. BMJ. 2004;329(7464):486. doi:10.1136/bmj.329.7464.486

16. International Study of Asthma and Allergies in Childhood. Available from: http://isaac.auckland.ac.nz/phases/phasetwo/phasetwomodules. pdf. Accessed November 29, 2011.

17. Brozek JL, Bousquet J, Baena-Cagnani CE, et al. Allergic rhinitis and its impact on asthma (ARIA) guidelines: 2010 revision. $J$ Allergy Clin Immunol. 2010;126(3):466-476. doi:10.1016/j.jaci.2010.06.047

18. Perkin MR, Bader T, Rudnicka AR, Strachan DP, Owen CG. Interrelationship between rhinitis and conjunctivitis in allergic rhinoconjunctivitis and associated risk factors in rural UK children. PLoS One. 2015;10(11):e0143651. doi:10.1371/journal.pone.0143651

19. Thong BY. Allergic conjunctivitis in Asia. Asia Pac Allergy. 2017;7 (2):57-64. doi:10.5415/apallergy.2017.7.2.57

20. Lou H, Ma S, Zhao Y, et al. Sensitization patterns and minimum screening panels for aeroallergens in self-reported allergic rhinitis in China. Sci Rep. 2017;7(1):9286. doi:10.1038/s41598-017-10111-9

21. Rosenfield L, Tsoulis MW, Milio K, Schnittke M, Kim H. High rate of house dust mite sensitization in a shrimp allergic southern Ontario population. Allergy Asthma Clin Immunol. 2017;13:5. doi:10.1186/ s13223-017-0177-x

22. Li J, Huang Y, Lin X, et al. Factors associated with allergen sensitizations in patients with asthma and/or rhinitis in China. Am J Rhinol Allergy. 2012;26(2):85-91. doi:10.2500/ajra.2012.26.3751

23. Kam AW, Tong WW, Christensen JM, Katelaris CH, Rimmer J, Harvey RJ. Microgeographic factors and patterns of aeroallergen sensitisation. Med J Aust. 2016;205(7):310-315. doi:10.5694/ mja16.00264 
24. Heinrich J, Bedada GB, Zock JP, et al. Cat allergen level: its determinants and relationship to specific $\operatorname{IgE}$ to cat across European centers. J Allergy Clin Immunol. 2006;118(3):674-681. doi:10.1016/ j.jaci.2006.06.012

25. Liccardi G, D’Amato G, Antonicelli L, et al. Sensitization to horse allergens in Italy: a multicentre study in urban atopic subjects without occupational exposure. Int Arch Allergy Immunol. 2011;155 (4):412-417. doi:10.1159/000321414

26. Hemmer W, Sestak-Greinecker G, Braunsteiner T, Wantke F, Wohrl S. Molecular sensitization patterns in animal allergy: relationship with clinical relevance and pet ownership. Allergy. 2021. doi:10.1111/all.14885

27. Dottorini ML, Bruni B, Peccini F, et al. Skin prick-test reactivity to aeroallergens and allergic symptoms in an urban population of central Italy: a longitudinal study. Clin Exp Allergy. 2007;37(2):188-196. doi:10.1111/j.1365-2222.2007.02652.x

28. Amritwar AU, Lowry CA, Brenner LA, et al. Mental health in allergic rhinitis: depression and suicidal behavior. Curr Treat Options Allergy. 2017;4(1):71-97. doi:10.1007/s40521-0170110-z
29. Hu WN, Zhu L, Xie LF, et al. Correlation between the visiting rate of patients with allergic rhinitis and airborne pollen concentrations in Beijing in recent 3 years. Zhonghua Er Bi Yan Hou Tou Jing Wai Ke Za Zhi. 2017;52(1):31-36. doi:10.3760/cma.j.issn.16730860.2017.01.006

30. Liao $\mathrm{C}$, Liang $\mathrm{C}, \mathrm{Hu} \mathrm{H}$, et al. Major pollen allergen components and CCD detection in Bermuda grass sensitized patients in Guangzhou, China. J Asthma Allergy. 2020;13:615-623. doi:10.2147/JAA.S277704

31. Canis M, Groger M, Becker S, Klemens C, Kramer MF. Recombinant marker allergens in diagnosis of patients with allergic rhinoconjunctivitis to tree and grass pollens. Am J Rhinol Allergy. 2011;25 (1):36-39. doi:10.2500/ajra.2011.25.3551

32. Di Stefano V, Battaglia G, Giustino V, et al. Significant reduction of physical activity in patients with neuromuscular disease during COVID-19 pandemic: the long-term consequences of quarantine. J Neurol. 2021;268(1):20-26. doi:10.1007/s00415-020-10064-6

33. Huang Y, Zhang Y, Zhang L. Prevalence of allergic and nonallergic rhinitis in a rural area of northern China based on sensitization to specific aeroallergens. Allergy Asthma Clin Immunol. 2018;14:77. doi:10.1186/s13223-018-0299-9

\section{Publish your work in this journal}

The Journal of Asthma and Allergy is an international, peer-reviewed open-access journal publishing original research, reports, editorials and commentaries on the following topics: Asthma; Pulmonary physiology; Asthma related clinical health; Clinical immunology and the immunological basis of disease; Pharmacological interventions and new therapies. The manuscript management system is completely online and includes a very quick and fair peer-review system, which is all easy to use. Visit http://www.dovepress.com/testimonials.php to read real quotes from published authors. 